\title{
Editorial
}

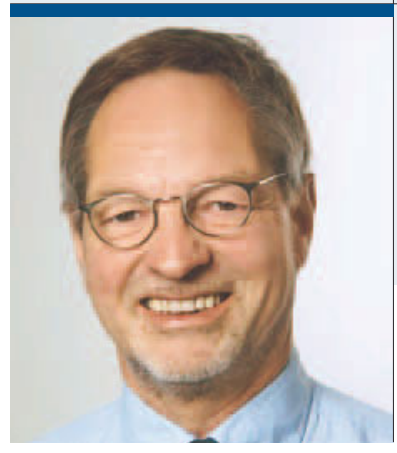

„Die Vorgehensweise, wie hier ein Gesetz unter Ignorierung der Expertenmeinung zustande kam, ist ein Skandal!"

Dr. med. Walther Grohmann

Chefredakteur und niedergelassener Urologe, München

\section{Handeln gegen besseres Wissen}

D er Skandal war perfekt: Statt der aktuellen Neujahrsansprache des damaligen Bundeskanzlers Helmut Kohl für das Jahr 1986 wurde im Fernsehen diejenige des Vorjahres ausgestrahlt - und manch einer hat das wohl gar nicht bemerkt. Vergleichbares hätte man mit diesem Editorial von URO-NEWS machen können: Die einleitende Seite in URO-NEWS $1 / 2010$ zur Onkologievereinbarung könnte hier bedauerlicherweise nahezu unverändert erneut abgedruckt werden. $\mathrm{Zu}$ ändern wäre lediglich die Überschrift. Statt „....denn sie wissen nicht, was sie tun!“ müsste stehen: „Handeln gegen besseres Wissen".

Denn dieses Handeln ist symptomatisch für unsere Gesundheitspolitik und betrifft auch das Arzneimittelmarkt-Neuordnungsgesetz (AMNOG). Vielen dürfte die Entstehungsgeschichte des Gesetzes und die ganze, dahinterstehende Wahrheit nicht bewusst sein. Dankenswerterweise gewährt uns Prof. Lothar Weißbach einen Blick hinter die Kulissen, wie das AMNOG zustande kam (Seite 12). Die Vorgehensweise, wie hier ein Gesetz unter Ignorierung der Expertenmeinung zustande kam, ist ein Skandal und es wäre kein Wunder, wenn hinterher zur Beschwichtigung wieder einmal gesagt würde „Aber Ihre Vertreter waren doch selbst dabei!“ Es bleibt die Frage, wie lange wir als Ärzte - und nicht nur als "Leistungserbringer" - bereit sind, derartiges hinzunehmen und wann ein Schlussstrich gezogen werden muss.

\section{Anerkennung für Mut zum Systemausstieg}

Einen vergleichbaren Schlussstrich wollten die bayerischen Hausärzte mit der Rückgabe ihrer Kassenzulassung am 22. Dezember 2010 in Nürnberg ziehen. Knapp $40 \%$ waren dazu bereit, ihre Kassenzulassung zurückzugeben. Das Ziel, die 60\%-Marke zu erreichen, wurde klar verfehlt und wesentliche Änderungen sind wohl auch nach Verlängerung der Zeit für die Abstimmung nicht zu erwarten. Dennoch verdienen diese knapp $40 \%$ der Hausärzte für ihren Mut unseren hohen Respekt. Der absolut unzulässige Umkehrschluss, dass somit $60 \%$ der Hausärzte das gegenwärtige System befürworten, wird wohl bald zu hören sein und in üblicher „Vernebelungs-Information" seine Verbreitung finden. Warten wir ab, ob aus diesem Schwelbrand nicht doch im Lauf des Jahres ein Flächenbrand wird. Noch unklar ist auch, was dieses Ergebnis der Hausärzte für uns Fachärzte und auch für ihr Korbmodell bedeutet. Hier wird noch viel zu analysieren und zu diskutieren sein.

Was aber die eingangs erwähnte, nach einem Jahr nochmals ausgestrahlte Neujahrsansprache von Helmut Kohl betrifft, so gibt es offensichtlich Schriftstücke, die auch nach über 70 Jahren fast unverändert aktuell sind. Hierzu gehört das Gedicht von Kurt Tucholsky alias Theobald Tiger über die Ortskrankenkasse, zu lesen auf Seite 52.

Alles Gute für das spannende und sicher beruflich nicht einfache Jahr 2011 wünscht Ihnen das Team von URO-NEWS!

Ihr

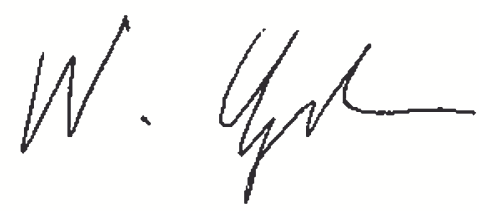

